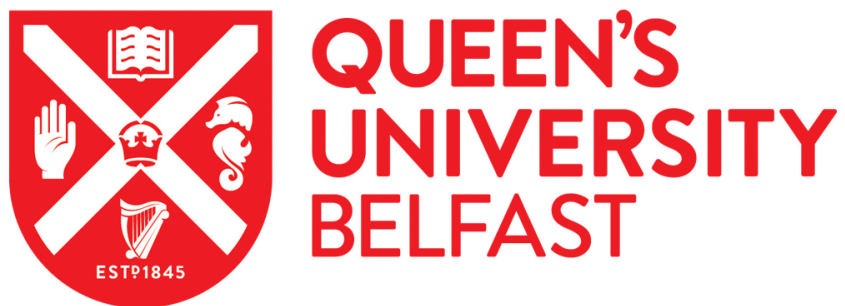

\section{Epidemiology of basal-like and luminal breast cancers among black women in the AMBER consortium}

\author{
Benefield, H. C., Zirpoli, G. R., Allott, E. H., Shan, Y., Hurson, A. N., Omilian, A. R., Khoury, T., Hong, C-C., \\ Olshan, A. F., Bethea, T. N., Bandera, E. V., Palmer, J. R., Ambrosone, C. B., \& Troester, M. A. (2020). \\ Epidemiology of basal-like and luminal breast cancers among black women in the AMBER consortium. Cancer \\ epidemiology, biomarkers \& prevention : a publication of the American Association for Cancer Research, \\ cosponsored by the American Society of Preventive Oncology. https://doi.org/10.1158/1055-9965.EPI-20-0556 \\ Published in: \\ Cancer epidemiology, biomarkers \& prevention : a publication of the American Association for Cancer Research, \\ cosponsored by the American Society of Preventive Oncology
}

\section{Document Version:}

Peer reviewed version

\section{Queen's University Belfast - Research Portal:}

Link to publication record in Queen's University Belfast Research Portal

\section{Publisher rights}

Copyright @2020, American Association for Cancer Research. This work is made available online in accordance with the publisher's policies Please refer to any applicable terms of use of the publisher.

\footnotetext{
General rights

Copyright for the publications made accessible via the Queen's University Belfast Research Portal is retained by the author(s) and / or other copyright owners and it is a condition of accessing these publications that users recognise and abide by the legal requirements associated
} with these rights.

Take down policy

The Research Portal is Queen's institutional repository that provides access to Queen's research output. Every effort has been made to ensure that content in the Research Portal does not infringe any person's rights, or applicable UK laws. If you discover content in the Research Portal that you believe breaches copyright or violates any law, please contact openaccess@qub.ac.uk. 
Title: Epidemiology of basal-like breast cancer among Black women in the AMBER consortium

Authors: Halei C. Benefield, Gary R. Zirpoli, Emma H. Allott, Yue Shan, Amber N. Wilcox, Angela R. Omilian, Thaer Khoury, Chi-Chen Hong, Andrew F. Olshan, Traci N. Bethea, Elisa V. Bandera, Julie R. Palmer, Christine B. Ambrosone, Melissa A. Troester

Affiliations: Halei C. Benefield, Amber N. Wilcox, Andrew F. Olshan, and Melissa A. Troester, Department of Epidemiology, University of North Carolina at Chapel Hill, Chapel Hill, NC, USA; Gary R. Zirpoli, Traci N. Bethea, and Julie R. Palmer, Slone Epidemiology Center at Boston University, Boston, MA, USA; Emma H. Allott, Patrick G Johnston Centre for Cancer Research, Queen's University Belfast, Belfast, United Kingdom; Yue Shan, Department of Biostatistics, University of North Carolina at Chapel Hill, Chapel Hill, NC, USA; Angela R. Omilian, Chi-Chen Hong, and Christine B. Ambrosone, Department of Cancer Prevention and Control, Roswell Park Comprehensive Cancer Center, Buffalo, NY, USA; Thaer Khoury, Department of Pathology, Roswell Park Cancer Institute, Buffalo, NY, USA; Elisa B. Bandera, Rutgers Cancer Institute of New Jersey, New Brunswick, NJ, USA

Running title: Basal-like breast cancer among Black women

Keywords (5): African American; Breast cancer; Basal-like; Epidemiology; Risk factors

Financial Support: This work was supported by a grant from the UNC Lineberger Comprehensive Cancer Center funded by the University Cancer Research Fund (LCCC2017T204), Susan G. Komen Foundation, the National Cancer Institute of the National Institutes of Health (P50-CA58223, U01-CA179715 to MAT, T32-CA057726 to HCB, F30CA236199 to HCB), the National Institute of Environmental Health Sciences of the National 
Institutes of Health (P30-ES010126 to MAT). HCB is a recipient of the Gertrude B. Elion Mentored Medical Student Research Award of Triangle Community Foundation.

\section{Conflicts of interest:}

Corresponding author: Melissa A. Troester, 253 Rosenau Hall, CB \#7435, 135 Dauer Dr. Chapel Hill, NC 27599-7400, Phone 919-966-7408, Fax 919-966-7408, Email troester@email.unc.edu

Word count: 3,060

\section{Total figures and tables: 4}

Abbreviations: African American Breast Cancer Epidemiology and Risk (AMBER), estrogen receptor (ER), progesterone receptor (PR), human epidermal growth factor receptor 2 (HER2), epidermal growth factor receptor (EGFR), cytokeratin (CK)5/6, odds ratios (ORs), body mass index (BMI), waist-to-hip ratio (WHR), immunohistochemical (IHC), Carolina Breast Cancer Study (CBCS), the Black Women's Health Study (BWHS), the Women's Circle of Health Study (WCHS), the Multi-Ethnic Cohort (MEC), New Jersey (NJ), confidence intervals (CIs), Akaike information criterion (AIC), Molecular Taxonomy of Breast Cancer International Consortium (METABRIC) 


\section{ABSTRACT}

Background: Evidence suggests etiologic heterogeneity among breast cancer subtypes. Previous studies with six-marker immunohistochemical classification of intrinsic subtypes included small numbers of Black women.

Methods: Using centralized laboratory results for estrogen receptor (ER), progesterone receptor (PR), human epidermal growth factor 2 (HER2), proliferation marker Ki-67, epidermal growth factor receptor (EGFR), and cytokeratin (CK)5/6, we estimated case-only and case-control odds ratios (ORs) for established breast cancer risk factors among cases $(n=2,354)$ and controls (n =2,932) in the African American Breast Cancer Epidemiology and Risk (AMBER) consortium. ORs were estimated by ER status and intrinsic subtype using adjusted logistic regression. Results: Case-only analyses by ER status showed etiologic heterogeneity by age at menarche, parity, and age at first birth. In case-control analyses for six-marker intrinsic subtype, increased body mass index (BMI) and waist-to-hip (WHR) ratio were associated with increased risk of luminal A subtype, while older age at menarche and parity, regardless of breastfeeding, were associated with reduced risk. For basal-like cancers, parity without breastfeeding and increasing WHR were associated with increased risk, whereas breastfeeding and age $\geq 25$ years at first birth were associated with reduced risk among parous women. Basal-like and ER-/HER2+ subtypes both had earlier age-at-incidence distribution relative to luminal subtypes.

Conclusions: Breast cancer subtypes show distinct etiologic profiles in the AMBER consortium, a study of over 5,000 Black women with centrally assessed tumor biospecimens.

Impact: Among Black women, high WHR and parity without breastfeeding are emerging as important intervention points to reduce the incidence of basal-like breast cancer. 


\section{INTRODUCTION}

Basal-like breast cancer is an aggressive molecular subtype defined by a signature of genes, including those expressed in the basal layer of human breast tissue. ${ }^{1}$ Basal-like tumors typically have poor clinical outcomes and limited options for targeted treatment due to low or absent expression of estrogen receptor (ER), progesterone receptor (PR), and human epidermal growth factor receptor 2 (HER2). ${ }^{2-7}$ Previous studies show that the relative frequency of basallike tumors is highest among younger women and Black women, especially premenopausal Black women. ${ }^{8-11}$ Reproductive factors, such as parity and breastfeeding, have been shown to contribute to the risk of basal-like subtype, with parous women who do not breastfeed having an increased risk of estrogen receptor (ER) negative and triple-negative breast cancer. ${ }^{9,12-14}$ Late age at menarche has been associated with reduced risk of ER-negative breast cancers among Black women. ${ }^{15}$ Associations with other hormone-related risk factors, such as body mass index and oral contraceptive use, have been inconsistent across studies of Black women. ${ }^{16-19}$

Accurate and reliable methods for determining breast tumor subtype are important in studies of risk factor heterogeneity. Most prior risk factor studies have relied on ER, PR, and HER2 status from the clinical record for classification of tumors as luminal A (ER+/HER2-), luminal B (ER+/HER2+), ER-/HER2+, and triple-negative (ER-/PR-/HER2-). ${ }^{20-24}$ However, laboratory technical variation, changes in expression cutoff values, and intratumoral heterogeneity can contribute to outcome misclassification within this schema, particularly for luminal breast cancers. Moreover, reliance on triple negative status from the clinical record has resulted in misclassification of basal-like breast cancers in some studies. ${ }^{25-28}$ We recently showed that incorporating centrally-assayed ER, PR, HER2, Ki67, EGFR, and CK5/6 immunohistochemical (IHC)-surrogate classification improved subtype accuracy and produced 
subtype frequencies similar to those from the RNA-based PAM50 intrinsic subtype assay in the African American Breast Cancer and Risk (AMBER) Consortium. ${ }^{29}$ Importantly, basal-like cancers were nearly as prevalent as luminal A subtype in this consortium study of Black patients. Thus, the AMBER consortium is well-powered for analysis of basal-like risk factor profiles. Since previous reports of the epidemiology of basal-like breast cancer relied on relatively few basal-like breast cancers (the largest to date enrolling $n=122$ Black women with basal-like subtype in Millikan et al. 2008; several smaller studies have examined triple-negative classified tumors), we sought to update estimates for risk factor associations in a more than five-fold larger population of Black women $\left(\mathrm{n}=691\right.$ basal-like breast cancers)..$^{9,20-24}$

\section{METHODS}

Study population. The AMBER consortium includes Black cases and controls from observational studies of breast cancer: the Carolina Breast Cancer Study (CBCS), the Black Women's Health Study (BWHS), the Women's Circle of Health Study (WCHS) and the MultiEthnic Cohort (MEC). Centralized IHC for intrinsic subtype was performed only for CBCS, BWHS and WCHS; MEC participants were not included in the analysis. Sampling schema for each study have been reported previously. ${ }^{30}$ Each study was approved by institutional review boards at participating hospitals and academic institutions. Briefly, the CBCS is a populationbased study of breast cancer cases in North Carolina that enrolled women in three phases (Phase 1: 1993-1996, Phase 2: 1996-2001 and Phase 3: 2008-2013) and oversampled young and Black women. The study identified cases via rapid case ascertainment and recruited controls using Division of Motor Vehicle and Medicare beneficiary lists. Phase 3 did not enroll controls; as a result, use of Phase 3 cases in this study is limited to our analyses of case-only ORs and age-atincidence curves. Data collection included in-person interview and medical record abstraction. 
BWHS enrolled 59,000 cancer-free Black women via a mailed questionnaire beginning in 1995 and have followed women through biennial questionnaire since. Breast cancer diagnoses are selfreported and confirmed via medical record linkage or through state cancer registries and the National Death Index. Three controls per case were included from the BWHS, frequencymatched to cases by 5 -year age category. The WCHS is a case-control study initially conducted in metropolitan New York City and later only in 10 counties in eastern New Jersey (NJ). New York cases with incident breast cancer from hospitals that served large proportions of Black cases and controls were identified through random digit dialing. In NJ, cases were identified through the NJ State Cancer Registry and controls using random digit dialing and communitybased recruitment; all data are collected through in-person interviews.

Eligible women for the present study included 1,559 cases from the CBCS (304 from Phase 1, 29 from Phase 2, and 1,226 from Phase 3), 291 cases from the BWHS, and 504 cases from the WCHS. Controls included 788 from Phases 1 and 2 of the CBCS, 873 from the BWHS, and 1,271 from the WCHS.

Tumor biomarkers. Eligible cases for the current analysis were women diagnosed with invasive breast cancer and for whom tumor tissue was available for centralized laboratory analysis $(\mathrm{n}=2,354)$. For all cases, IHC biomarker stains were carried out on paraffin-embedded tumor sections or tumor microarrays at the Translational Pathology Lab at the University of North Carolina at Chapel Hill using assay procedures and cutpoints as previously described..$^{29} \mathrm{~A}$ $10 \%$ ER positivity threshold was used to delineate ER-positive versus -negative. Subtypes were defined using 6 biomarkers: luminal A (ER+ and/or PR+, Ki-67 $<7.1 \%$ ), luminal B ( ER+ and/or PR+, Ki-67 $\geq 7.1 \%]$ ), ER-/HER2+, or triple negative (ER- and PR- and HER2- and [EGFR+ or CK5/6+]). When ER+ cases were missing Ki-67 (333 cases from CBCS; 0 cases 
from BWHS; 51 cases from WCHS), subtypes were defined using 5 biomarkers: luminal A (ER+ and/or PR+ and grade 1 or grade 2), luminal B (ER+ and/or PR+ and grade 3), ER-/HER2+, or triple negative (ER- and PR- and HER2- and [EGFR+ or CK5/6+]). 20 cases were additionally missing grade, and were included only in analyses stratified on ER status.

Statistical analyses. ORs were calculated as the measure of association between risk factor exposure and breast cancer subtype. Multivariable binomial logistic regression was used to calculate case-control and case-only ORs and 95\% confidence intervals (CIs). Multivariable models were adjusted for age (continuous linear), first degree family history of breast cancer (yes or no), parity (nulliparous, $1-2$ children, or $\geq 3$ children), breastfeeding duration (never, $<6$ months, or $\geq 6$ months), and study (CBCS, WCHS, BWHS). P-values were two-sided with $\alpha=$ 0.05 .

To compare the joint impact of parity and breastfeeding on risk of luminal A and basallike subtypes, we used a composite variable categorizing parous women by breastfeeding status ( 1 or 2 children, never lactated; 3 or more children, never lactated; 1 or 2 children, ever lactated; 3 or more children, ever lactated) and calculated case-control ORs with nulliparous controls as the referent group.

Bimodality in age at diagnosis has been used to investigate etiologically distinct subtypes of breast cancer. ${ }^{31}$ We use two-component statistical mixture models to estimate the proportions of early-onset and late-onset cases within each of the intrinsic subtypes, as previously described. ${ }^{31,32}$ Within each subtype we compared the fit of single-density models versus twocomponent mixture models. For each type of model we implemented both normal density and semi-nonparametric density models (adding polynomial multiplier to the normal distribution to allow for skewness and heavy tails in the distributions), resulting in a total of four models for 
each subtype. The four models fitted for each subtype were compared using Akaike information criterion (AIC) values, with smaller AIC values indicating a better fit. We identified the best fitting single-density model and the best fitting two-component mixture model, and then compared the goodness of fit between these two models using the difference in their AIC values ( $\triangle \mathrm{AIC}) . \triangle \mathrm{AIC}>10$ indicated a substantial difference in the goodness of fit between the two models. For each subtype we plotted the smoothed density curve estimated from the best model overlaid with the empirical age-at-diagnosis distribution (i.e. histogram) for early onset, late onset and overall distribution. All analyses were performed using SAS 9.4 (SAS Institute, Cary, NC) and R (version 3.4.3, R Foundation for Statistical Computing, Vienna, Austria).

\section{RESULTS}

Case-only odds ratios for ER-positive and ER-negative tumors. Estrogen receptor is a strong marker of etiologic heterogeneity in previous studies of breast cancer in Black and White women. To first establish the similarity of this dataset to previous studies with respect to ER heterogeneity, we evaluated case-only ORs for a range of risk factors comparing ER-negative tumors to ER-positive tumors. Multivariable ORs are presented in Table 1. Older age at menarche, increasing parity, age at first full term birth, and breastfeeding status showed etiologic heterogeneity by ER status. Family history, oral contraceptive use, BMI, and WHR did not show significant heterogeneity by ER status.

Case-control odds ratios for IHC intrinsic subtype. Case-control ORs were estimated for subtype based on 6-marker central IHC (Table 2). Subtype distribution by study site has been previously reported. ${ }^{29}$ Luminal A subtype was positively associated with increasing BMI and increasing WHR. Older age at menarche and parity, regardless of breastfeeding status, were associated with reduced risk of luminal A subtype. Associations for luminal B breast cancer were 
similar to those for Luminal A but closer to the null, except for family history of breast cancer, which was significantly associated with luminal B risk. The direction of associations for ER/HER2+ tumors were similar to those for luminal A, with family history, oral contraceptive use and age $\geq 25$ years at first birth strongly positively associated and parity inversely associated with risk of ER-/HER2+. Basal-like breast cancer showed distinct risk factors. Parity was not found to be protective for basal-like breast cancer, and instead was associated with elevated ORs in case-control analyses. Increasing WHR and higher parity without breastfeeding were significantly associated with increased risk of basal-like, while breastfeeding and age $\geq 25$ years at first birth were protective among parous women.

Case-only odds ratios for IHC intrinsic subtype. Case-only ORs were calculated to allow evaluation of etiologic heterogeneity by 6-marker subtype. Risk factor profiles for luminal B, ER-/HER2+ and basal-like breast tumors were estimated relative to luminal A subtype (Table 3). Overall, consistent with case-control findings, the luminal A and luminal B subtypes showed similar risk factor profiles, demonstrated by the non-significant case-only ORs for luminal B tumors. Case-only analyses highlighted differences between luminal A and ER-/HER2+ and basal-like etiology. Increased parity was associated with higher odds of basal-like but decreased odds of HER2-subtype compared to luminal A subtype. Breastfeeding was associated with decreased odds for both ER-/HER2+ and basal-like breast cancers relative to luminal A. Similar to case-control analyses, age $\geq 25$ years at first birth was protective for basal-like cancers among parous women. Age at menarche, oral contraceptive use, BMI, and WHR did not show significant heterogeneity by intrinsic subtype.

Age-at-incidence curves. Bimodal frequency distributions for age at incidence have been interpreted as evidence of etiologic heterogeneity for basal-like vs. luminal A tumors. We 
applied two-component mixture models among all cases and within each intrinsic subtype and compared them with single density models to evaluate the presence of bimodality in age at diagnosis. We then plotted the smoothed density plots overlaid with histograms to show the distribution of cases by age at diagnosis (Figure 1). We found that luminal cancers were best represented by a two-component mixture model (Supplemental Table 1). For the basal-like group, $\triangle \mathrm{AIC}$ lay between 4-10, still indicating that the two-component mixture model provided better fit, albeit with slightly lower certainty than for luminal cancers. For ER-/HER2+, we could not distinguish which model provided the better fit, with $\triangle \mathrm{AIC}<4$. Broadly, luminal A tumors showed a strongly bimodal pattern in age at diagnosis, with enrichment for both early and late onset disease. Luminal B subtype had a less pronounced late onset peak. ER-/HER2+ subtype was skewed toward earlier age at incidence, with a strong early-onset peak. Basal-like subtype was similarly enriched for early-onset disease, showing a small late-onset peak.

\section{DISCUSSION}

We estimated associations between breast cancer risk factors and tumor subtypes defined by six-marker IHC classification among Black women in the AMBER consortium. We found breastfeeding to be protective for basal-like and ER-/HER2+ breast cancer in both case-control and case-only analyses. Parity and later age at menarche were associated with reduced risk of luminal A breast cancer, while increased BMI and WHR conferred increased risk. Luminal B subtype was not significantly associated with any risk factors other than family history, although the direction of association was similar for Luminal A breast cancers, and in case-only analyses did not exhibit a risk factor profile distinct from luminal A. Age-at-incidence curves overall showed bimodal distributions with pronounced early onset peaks for all subtypes, but ER/HER2+ and basal-like subtypes showed earlier age at diagnosis compared to luminal subtypes, 
in keeping with their distinct risk factor profiles. In a large, Black population with centrallyassessed, six-marker IHC-based breast cancer subtypes, risk factor profiles by intrinsic subtype suggest distinct risk factors for basal-like breast cancer and highlight breastfeeding as a plausible intervention to reduce risk of this aggressive subtype of breast cancer.

Breastfeeding has consistently demonstrated a protective effect for triple negative and basal-like breast cancers in prior literature. ${ }^{33-40}$ In our study, we observed that women who were parous but did not breastfeed had the highest ORs for basal-like breast cancer, further reinforcing the importance of breastfeeding to reduce risk of basal-like breast cancer. A number of prior studies have found similar results, including earlier analyses with clinical markers in the AMBER consortium, which found breastfeeding to be associated with reduced risk for ERnegative, basal-like, and triple-negative subtypes, while parous women who did not breastfeed were at increased risk for these subtypes. ${ }^{9,13,34,41}$ We also found increased WHR to be associated with increased risk of basal-like subtype, in agreement with earlier analyses in the AMBER consortium. ${ }^{16,18}$ A previous study among participants of the Women's Health Initiative showed no association between WHR and risk for triple negative breast cancer; however, this study included a small number of Black women ( $n=199$ cases). ${ }^{42}$ The relationship between adiposity and breast cancer risk appears to vary by race and ethnicity, and WHR, commonly used to represent central adiposity, may more strongly influence breast cancer risk than BMI among Black women. ${ }^{43}$ It will be important to consider obesity-related biomarkers in future studies to better understand how body mass distribution and race influence breast cancer etiology.

Compared to luminal and basal-like subtypes, risk factor profiles for luminal B and ER/HER2+ breast cancer have been less consistently reported, likely due to the lower prevalence of these subtypes. However, considering the magnitude of associations in prior literature, there 
appears to be an overlapping risk factor profile for luminal A and B subtypes, in line with what we found. ${ }^{33,35,36,44}$ As for the ER-/HER2+ subtype, we found several significant associations, including a protective effect of parity with breastfeeding. Unlike for basal-like breast cancer, parity alone was protective for ER-/HER2+ subtype. This is in contrast to a study among a multiethnic cohort of women which found parity to be associated with $43 \%$ (95\% CI: $1.08-1.89$ ) higher odds of ER-/HER2+ breast cancer relative to luminal A. ${ }^{41}$ That study included a larger number $(\mathrm{n}=493)$ of ER-/HER2+ tumors and a lower proportion (less than 6\%) of Black women relative to our study. In the Nurses Health Study, a cohort of largely non-Hispanic White women, Fortner et al. also found parity to be associated with increased risk of ER-/HER2+ tumors. ${ }^{35}$ Our discrepant findings may be due to differences in tumor classification schema and/or patient population, as reproductive factors are known to vary by race and ethnicity. ${ }^{45,46}$ Of note, we found an increased risk for ER-/HER2+ subtype with oral contraceptive use, a finding that has been previously reported among White and Asian women, but not among Black women. ${ }^{47-49}$

Age at incidence curves offer additional perspectives on etiologic heterogeneity among breast tumor subtypes. Recent evidence has suggested that breast cancer can be divided into two etiologic subtypes defined by age at onset, and that the difference in the relative distribution of those two subtypes underpins the biological characteristics of any given breast cancer categorization. ${ }^{50}$ We saw that, compared to the luminal subtypes, ER-/HER2+ and basal-like subtypes exhibited strong early onset peaks, which supports the distinct risk factor associations found in case-only analyses. However, it is notable that predominant early onset enrichment was observed among all subtypes in this study of Black women. This is in contrast to an earlier study using data from the Molecular Taxonomy of Breast Cancer International Consortium (METABRIC), which enrolled mostly White women, and showed luminal A and luminal B 
subtypes to have predominant late onset modes ${ }^{51}$ Our findings confirm a consistent trend toward earlier age at breast cancer incidence for Black women compared to White women and suggest that it persists across all subtypes. ${ }^{31,52,53}$

Strengths of this study include a large population of Black women from throughout the United States and the use of central laboratory, 6-marker IHC classification. The sample size of ER-/HER2+ and basal-like breast cancers is also much higher than previous studies of these subtypes in diverse populations. However, despite being one of the largest cohorts of Black women with breast cancer, we still lacked precision in measuring risk factor associations for the less common luminal B and ER-/HER2+ subtypes. Additionally, some associations were not statistically significant in case-control analyses, but the magnitude of these associations are important for interpretation of case-only analyses, which include larger sample sizes. It is also important to note that the modes for early and late age at incidence cannot be generalized to women in the source populations because some studies in the AMBER consortium oversampled for younger women. However, the modes were stable across intrinsic subtype, allowing for comparison of age-at-incidence curves by subtype.

Previous studies with diverse populations have found similar risk factors for basal-like breast cancer. However, in these earlier analyses, aggregation of risk factor patterns by race, including a trend toward earlier births and lower breastfeeding rates in Black women, remained a concern for etiologic inference. This study shows that even among a population entirely composed of Black women, reproductive and body size patterns were associated with this more aggressive breast cancer subtype. Future research to understand the mechanisms underlying these associations are needed. Additional approaches such as studies of second primary breast cancers may offer more direct evidence for etiologic heterogeneity. However, the current results suggest 
that continued promotion of breastfeeding as well as improved understanding of the biologic mechanisms linking adiposity and basal-like breast cancer risk should be part of a comprehensive strategy to address breast cancer disparities. 
Table 1: Case-only odds ratios comparing ER-negative relative to ER-positive breast cancer. Cases are from BWHS, WCHS, and CBCS Phases 1, 2, and 3.

\begin{tabular}{|c|c|c|c|}
\hline \multirow[b]{2}{*}{ Risk Factor } & \multirow{2}{*}{$\begin{array}{c}\text { ER-Positive } \\
(\mathrm{n}=1393) \\
\mathbf{n}(\%)\end{array}$} & \multicolumn{2}{|c|}{$\begin{array}{c}\text { ER-Negative } \\
(\mathrm{n}=956)\end{array}$} \\
\hline & & n $(\%)$ & OR $(95 \% C I)^{a}$ \\
\hline \multicolumn{4}{|l|}{ Family history } \\
\hline No & $1147(82)$ & $793(83)$ & 1.00 \\
\hline Yes & $246(18)$ & $163(17)$ & $1.03(0.82-1.29)$ \\
\hline \multicolumn{4}{|l|}{ Age at menarche } \\
\hline$<11$ & $164(12)$ & $96(10)$ & 1.00 \\
\hline $11-12$ & $630(45)$ & $413(43)$ & $1.15(0.86-1.54)$ \\
\hline$>=13$ & $597(43)$ & 446 (47) & $1.35(1.01-1.80)$ \\
\hline Missing & 2 & 1 & \\
\hline \multicolumn{4}{|l|}{ Parity } \\
\hline Nulliparous & $242(17)$ & $114(12)$ & 1.00 \\
\hline 1-2 children & $661(47)$ & $492(51)$ & $1.87(1.43-2.44)$ \\
\hline$>=3$ children & $490(35)$ & $350(37)$ & $2.05(1.54-2.73)$ \\
\hline Missing & 0 & 0 & \\
\hline \multicolumn{4}{|l|}{ Age at first full-term birth ${ }^{\mathrm{b}}$} \\
\hline$<25$ & $808(70)$ & $643(76)$ & 1.00 \\
\hline$>=25$ & $337(30)$ & $196(23)$ & $0.74(0.60-0.92)$ \\
\hline Missing & 6 & 3 & \\
\hline \multicolumn{4}{|l|}{$\begin{array}{l}\text { Lifetime breastfeeding } \\
\text { duration }^{\mathrm{b}}\end{array}$} \\
\hline Never & $640(56)$ & $538(64)$ & 1.00 \\
\hline$<6 \mathrm{mos}$ & $205(18)$ & $144(17)$ & $0.75(0.59-0.96)$ \\
\hline $6+\operatorname{mos}$ & $297(26)$ & $154(18)$ & $0.61(0.49-0.78)$ \\
\hline Missing & 9 & 6 & \\
\hline \multicolumn{4}{|l|}{ Oral contraceptive use } \\
\hline Never & $559(40)$ & $339(35)$ & 1.00 \\
\hline Ever & $823(59)$ & $611(64)$ & $1.02(0.85-1.23)$ \\
\hline Missing & 11 & 0 & \\
\hline \multicolumn{4}{|l|}{ Body mass index } \\
\hline$<25$ & $228(16)$ & $155(16)$ & 1.00 \\
\hline $25-29$ & 367 (26) & $285(30)$ & $1.22(0.94-1.59)$ \\
\hline$>=30$ & $782(56)$ & $506(53)$ & $1.04(0.82-1.33)$ \\
\hline Missing & 16 & 10 & \\
\hline \multicolumn{4}{|l|}{ Waist-to-hip ratio } \\
\hline$<0.77$ & $164(12)$ & $116(12)$ & 1.00 \\
\hline $0.77-0.83$ & $343(25)$ & $287(30)$ & $1.18(0.87-1.59)$ \\
\hline$>=0.84$ & $837(60)$ & $528(55)$ & $0.97(0.73-1.29)$ \\
\hline Missing & 49 & 25 & \\
\hline
\end{tabular}

${ }^{a}$ Model includes: age, family history, parity, breastfeeding duration, and study.

bIncludes parous women only 
Table 2: Case-control odds ratios for six-marker breast cancer subtypes among cases from BWHS, WCHS, and CBCS Phases 1 and 2.

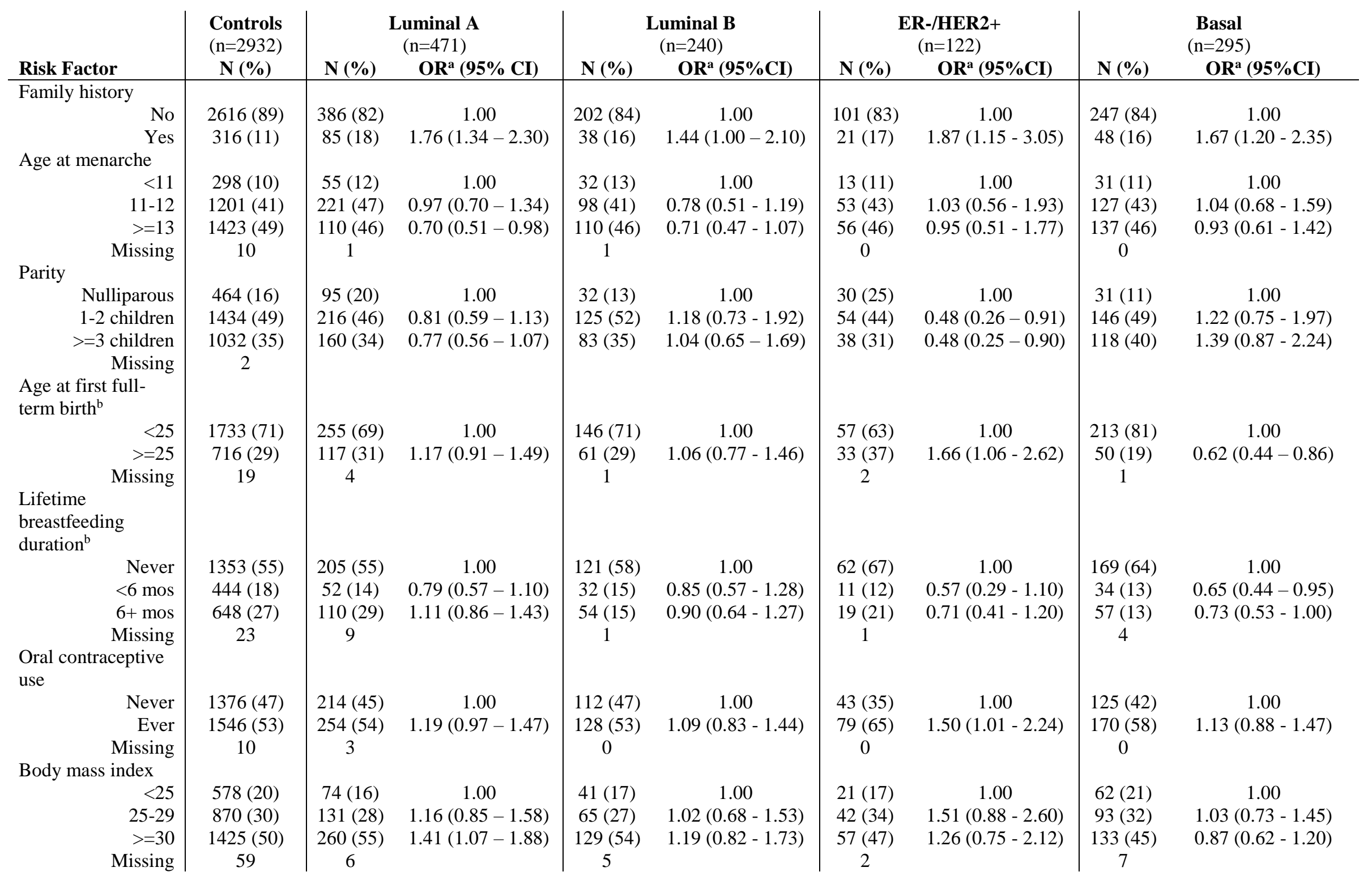




\begin{tabular}{|c|c|c|c|c|c|c|c|c|c|}
\hline $\begin{array}{r}\text { Waist-to-hip ratio } \\
<0.77\end{array}$ & $576(20)$ & 74 (16) & 1.00 & $32(13)$ & 1.00 & 23 (19) & 1.00 & 41 (14) & 1.00 \\
\hline $0.77-0.83$ & $778(28)$ & $116(25)$ & $1.24(0.90-1.71)$ & $54(23)$ & $1.08(0.68-1.72)$ & $35(29)$ & $1.18(0.68-2.06)$ & $89(30)$ & $1.49(1.00-2.21)$ \\
\hline$>=0.84$ & $1472(52)$ & $262(56)$ & $1.43(1.06-1.94)$ & $143(60)$ & $1.31(0.85-2.01)$ & $58(48)$ & $1.25(0.74-2.11)$ & $154(52)$ & $1.45(0.99-2.12)$ \\
\hline Missing & 106 & 19 & & 11 & & 6 & & 11 & \\
\hline $\begin{array}{l}\text { Parity and } \\
\text { breastfeeding }\end{array}$ & & & & & & & & & \\
\hline Nulliparous & $464(16)$ & $95(20)$ & 1.00 & $32(13)$ & 1.00 & $30(25)$ & 1.00 & $31(11)$ & 1.00 \\
\hline $1-2$, never & $833(28)$ & $128(27)$ & $0.74(0.55-0.99)$ & $81(34)$ & $1.37(0.90-2.11)$ & $40(33)$ & $0.72(0.44-1.18)$ & $99(34)$ & $1.70(1.11-2.60)$ \\
\hline $3+$, never & $520(18)$ & $77(16)$ & $0.68(0.49-0.95)$ & $40(17)$ & $1.06(0.65-1.73)$ & $22(18)$ & $0.62(0.34-1.10)$ & $70(24)$ & $1.84(1.17-2.90)$ \\
\hline 1-2, ever & $582(20)$ & $81(17)$ & $0.69(0.50-0.95)$ & $44(18)$ & $1.06(0.66-1.70)$ & $14(11)$ & $0.38(0.20-0.72)$ & $43(15)$ & $1.10(0.68-1.78)$ \\
\hline $3+$, ever & $510(17)$ & $81(17)$ & $0.72(0.51-0.99)$ & $42(18)$ & $1.13(0.69-1.83)$ & $16(13)$ & $0.51(0.27-0.97)$ & $48(16)$ & $1.40(0.87-2.26)$ \\
\hline Missing & 23 & 9 & & 1 & & 0 & & 4 & \\
\hline
\end{tabular}

${ }^{\mathrm{a}}$ Model adjusts for age, family history, parity, breastfeeding duration, and study site. ${ }^{\mathrm{b}}$ Among parous women only 
Table 3: Case-only odds ratios comparing six-marker subtypes of breast cancer among cases from BWHS, WCHS, and CBCS Phases 1-3.

\begin{tabular}{|c|c|c|c|c|c|c|c|}
\hline \multirow[b]{2}{*}{ Risk Factor } & \multirow{2}{*}{$\begin{array}{c}\text { Luminal A } \\
\begin{array}{c}(\mathrm{n}=827) \\
\mathbf{N}\end{array} \\
\end{array}$} & \multirow{2}{*}{\multicolumn{2}{|c|}{$\begin{array}{l}\text { Luminal B } \\
\qquad(\mathrm{n}=626) \\
\text { OR }(95 \% \mathrm{CI})\end{array}$}} & \multicolumn{2}{|r|}{$\begin{array}{c}\text { ER-/HER2+ } \\
(\mathrm{n}=210)\end{array}$} & \multicolumn{2}{|r|}{$\begin{array}{c}\text { Basal } \\
(\mathrm{n}=691)\end{array}$} \\
\hline & & & & $\mathbf{N}$ & OR $(95 \% \mathrm{CI})$ & $\mathbf{N}$ & OR $(95 \% \mathrm{CI})$ \\
\hline \multicolumn{8}{|l|}{ Family history } \\
\hline No & 664 & 535 & 1.00 & 177 & 1.00 & 568 & 1.00 \\
\hline Yes & 163 & 91 & $0.70(0.53-0.93)$ & 33 & $0.84(0.55-1.27)$ & 123 & $0.93(0.71-1.21)$ \\
\hline \multicolumn{8}{|l|}{ Age at menarche } \\
\hline 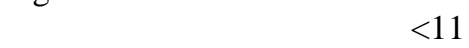 & 90 & 79 & 1.00 & 22 & 1.00 & 70 & 1.00 \\
\hline $11-12$ & 386 & 269 & $0.81(0.57-1.14)$ & 91 & $0.97(0.57-1.64)$ & 298 & $0.99(0.69-1.42)$ \\
\hline$>=13$ & 350 & 277 & $0.92(0.65-1.31)$ & 97 & $1.23(0.73-2.09)$ & 322 & $1.19(0.83-1.71)$ \\
\hline Missing & 1 & 1 & & 0 & & 1 & \\
\hline \multicolumn{8}{|l|}{ Parity } \\
\hline Nulliparous & 146 & 108 & 1.00 & 47 & 1.00 & 57 & 1.00 \\
\hline 1-2 children & 377 & 314 & $0.98(0.68-1.41)$ & 91 & $0.58(0.34-0.99)$ & 374 & $1.74(1.16-2.62)$ \\
\hline$>=3$ children & 304 & 204 & $0.80(0.55-1.15)$ & 72 & $0.66(0.39-1.12)$ & 260 & $1.66(1.10-2.49)$ \\
\hline \multicolumn{8}{|l|}{ Age at first full-term birth } \\
\hline$<25$ & 483 & 361 & 1.00 & 111 & 1.00 & 498 & 1.00 \\
\hline$>=25$ & 193 & 156 & $1.12(0.87-1.46)$ & 50 & $1.13(0.77-1.67)$ & 135 & $0.70(0.54-0.92)$ \\
\hline Missing & 5 & 1 & & 2 & & 1 & \\
\hline \multicolumn{8}{|l|}{ Lifetime breastfeeding duration* } \\
\hline Never & 376 & 297 & 1.00 & 101 & 1.00 & 405 & 1.00 \\
\hline$<6 \operatorname{mos}$ & 111 & 101 & $1.12(0.82-1.53)$ & 28 & $0.81(0.50-1.31)$ & 110 & $0.84(0.62-1.14)$ \\
\hline $6+\operatorname{mos}$ & 185 & 119 & $0.84(0.64-1.11)$ & 33 & $0.64(0.42-1.00)$ & 115 & $0.60(0.45-0.79)$ \\
\hline Missing & 9 & 1 & & 1 & & 4 & \\
\hline \multicolumn{8}{|l|}{ Oral contraceptive use } \\
\hline Never & 336 & 252 & 1.00 & 69 & 1.00 & 243 & 1.00 \\
\hline Ever & 484 & 370 & $0.89(0.71-1.12)$ & 140 & $1.13(0.81-1.58)$ & 443 & $1.01(0.81-1.27)$ \\
\hline Missing & 7 & 4 & & 1 & & 5 & \\
\hline \multicolumn{8}{|l|}{ Body mass index } \\
\hline$<25$ & 132 & 104 & 1.00 & 37 & 1.00 & 110 & 1.00 \\
\hline $25-29$ & 224 & 160 & $0.94(0.67-1.32)$ & 74 & $1.32(0.83-2.09)$ & 196 & $1.11(0.80-1.55)$ \\
\hline$>=30$ & 462 & 355 & $1.01(0.75-1.37)$ & 96 & $0.89(0.57-1.38)$ & 378 & $1.04(0.77-1.41)$ \\
\hline Missing & 9 & 7 & & 3 & & 7 & \\
\hline \multicolumn{8}{|l|}{ Waist-to-hip ratio } \\
\hline$<0.77$ & 101 & 74 & 1.00 & 32 & 1.00 & 73 & 1.00 \\
\hline $0.77-0.83$ & 204 & 158 & $0.89(0.61-1.31)$ & 64 & $1.03(0.62-1.70)$ & 206 & $1.24(0.85-1.82)$ \\
\hline$>=0.84$ & 493 & 373 & $0.90(0.63-1.28)$ & 107 & $0.84(0.52-1.37)$ & 395 & $1.06(0.74-1.52)$ \\
\hline Missing & 29 & 21 & & 7 & & 17 & \\
\hline
\end{tabular}


Parity and breastfeeding

$$
\begin{array}{r}
\text { Nulliparous } \\
1-2, \text { never } \\
3+, \text { never } \\
1-2, \text { ever } \\
3+\text {, ever } \\
\text { Missing }
\end{array}
$$

*Includes parous women only

\begin{tabular}{c|cc|cc|cc} 
& & & & & \\
146 & 108 & 1.00 & 47 & 1.00 & 57 & 1.00 \\
218 & 190 & $1.16(0.84-1.59)$ & 63 & $1.00(0.64-1.55)$ & 252 & $3.04(2.11-4.37)$ \\
158 & 107 & $0.89(0.62-1.27)$ & 38 & $0.90(0.55-1.49)$ & 153 & $2.58(1.74-3.81)$ \\
152 & 124 & $1.06(0.75-1.50)$ & 28 & $0.55(0.32-0.93)$ & 118 & $1.89(1.27-2.80)$ \\
144 & 96 & $0.91(0.63-1.31)$ & 33 & $0.85(0.51-1.42)$ & 107 & $2.06(1.37-3.09)$ \\
9 & 1 & & 1 & & 4 &
\end{tabular}


Supplemental Table 1: Estimates for early-onset and late-onset modes and mixing proportions by subtype.

\begin{tabular}{|c|c|c|c|c|c|c|c|c|c|}
\hline & \multirow{2}{*}{$\begin{array}{l}\text { Total } \\
\text { cases, } \\
\text { n }(\%)\end{array}$} & \multirow{2}{*}{$\begin{array}{l}\text { Median } \\
\text { age at } \\
\text { diagnosis } \\
\text { (years) }\end{array}$} & \multicolumn{3}{|c|}{ Model fit (AIC) } & \multicolumn{2}{|c|}{ Mode $^{b}$ (years) } & \multicolumn{2}{|c|}{$\begin{array}{c}\text { Mixing } \\
\text { proportion }^{b}\end{array}$} \\
\hline & & & $\begin{array}{c}\text { AIC } C_{\text {single }} \\
\text { density }\end{array}$ & $\begin{array}{c}\mathrm{AIC}_{\text {two- }} \\
\text { component mixture }\end{array}$ & $\begin{array}{c}\Delta \Delta_{\text {AIC }}{ }^{\mathrm{a}} \\
\left(\text { AIC }_{\text {single }}-\right. \\
\left.\text { AIC }_{\text {mixture }}\right)\end{array}$ & $\begin{array}{l}\text { Early } \\
\text { onset }\end{array}$ & $\begin{array}{l}\text { Late } \\
\text { onset }\end{array}$ & $\begin{array}{l}\text { Early } \\
\text { onset }\end{array}$ & $\begin{array}{l}\text { Late } \\
\text { onset }\end{array}$ \\
\hline Intrinsic subtype & & & & & & & & & \\
\hline All cases & 2354 & 51 & 18024.7 & 17952.8 & 71.9 & 49 & 67 & 0.86 & 0.14 \\
\hline Luminal A & 827 & 54 & 6331.3 & 6311.8 & 19.5 & 49 & 66 & 0.69 & 0.31 \\
\hline Luminal B & 626 & 51 & 4829.8 & 4805.7 & 24.0 & 48 & 67 & 0.81 & 0.19 \\
\hline ER-/HER2+ & 210 & 48 & 1569.5 & 1569.0 & 0.5 & 47 & 67 & 0.91 & 0.09 \\
\hline Basal-like & 691 & 49 & 5226.1 & 5219.7 & 6.5 & 46 & 62 & 0.75 & 0.25 \\
\hline
\end{tabular}

aPositive values favor the two-component mixture model, with $\Delta_{\mathrm{AIC}}>2$ indicating little support for the lower-ranking model and $\Delta_{\mathrm{AIC}}$ $>10$ indicating essentially no support for the lower-ranking model.

bModes and mixing proportions are shown for the two-component mixture model 
Figure 1. Density plots showing age frequency distributions at diagnosis for invasive breast cancer cases from AMBER, overall and by 6-marker IHC-based subtype

All cases $(n=2,354)$
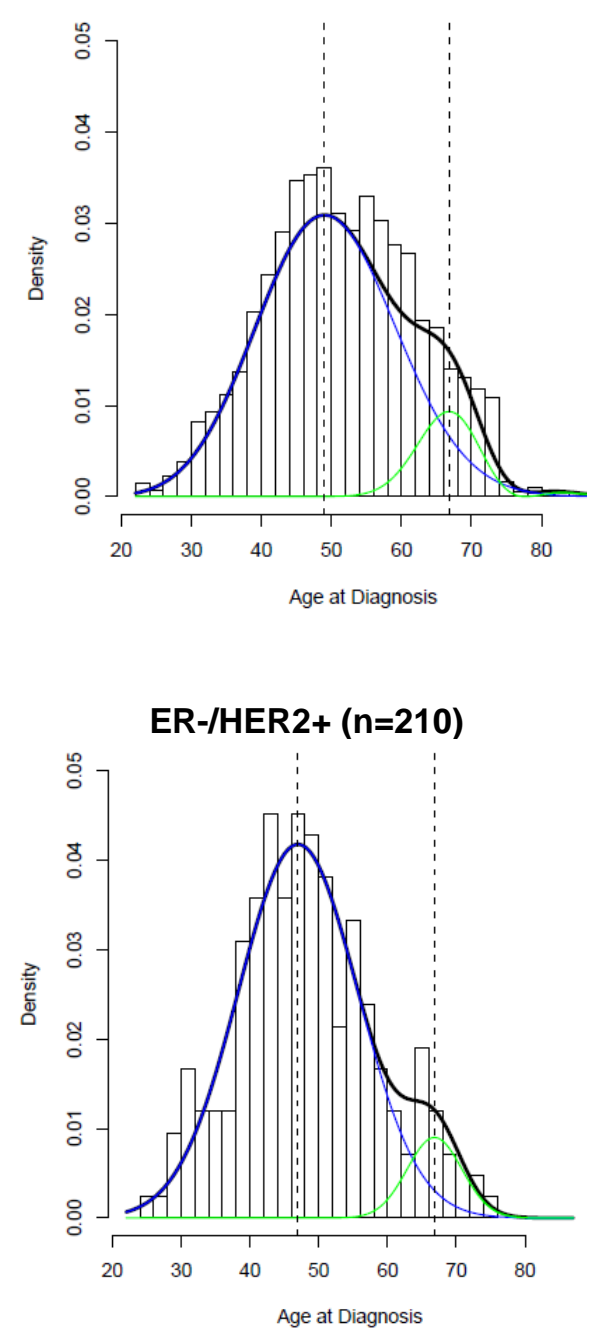

Luminal A ( $n=827)$

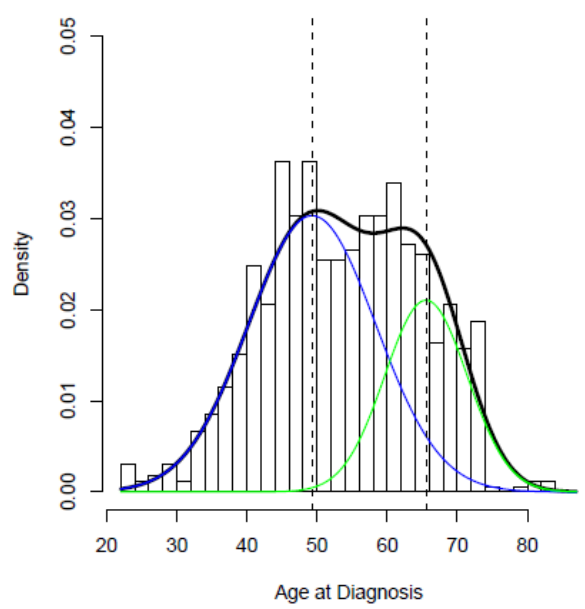

Basal-like $(n=691)$

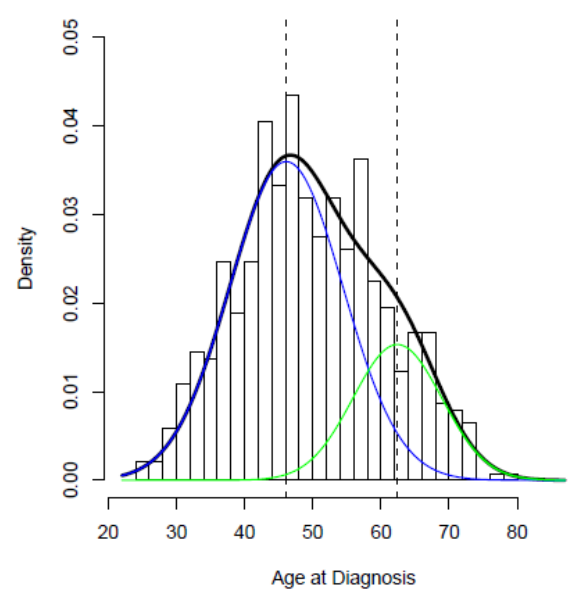

Luminal $B(n=626)$

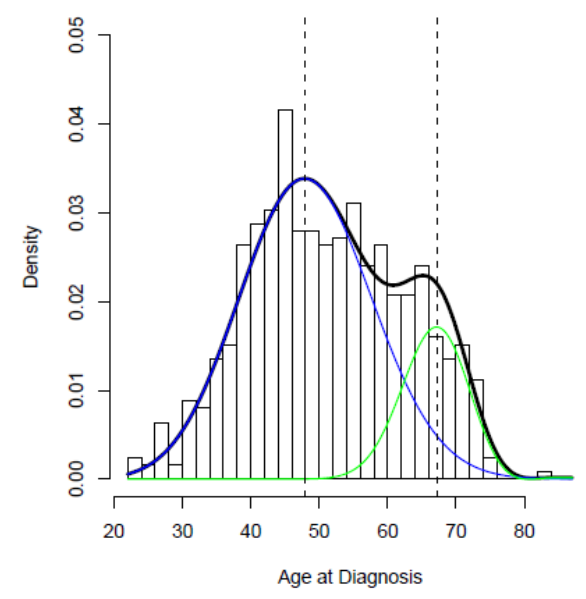




\section{References}

1. Parker JS, Mullins M, Cheang MCU, et al. Supervised risk predictor of breast cancer based on intrinsic subtypes. J Clin Oncol. 2009;27(8):1160-1167. doi:10.1200/JCO.2008.18.1370

2. Carey LA, Perou CM, Livasy CA, et al. Race, Breast Cancer Subtypes, and Survival in the Carolina Breast Cancer Study. JAMA. 2006;295(21):2492. doi:10.1001/jama.295.21.2492

3. Kroenke $\mathrm{CH}$, Sweeney $\mathrm{C}$, Kwan ML, et al. Race and breast cancer survival by intrinsic subtype based on PAM50 gene expression. Breast Cancer Res Treat. 2014;144(3):689699. doi:10.1007/s10549-014-2899-5

4. Caan BJ, Sweeney C, Habel LA, et al. Intrinsic subtypes from the PAM50 gene expression assay in a population-based breast cancer survivor cohort: prognostication of short- and long-term outcomes. Cancer Epidemiol Biomarkers Prev. 2014;23(5):725-734. doi:10.1158/1055-9965.EPI-13-1017

5. Khoury MJ, Flanders WD. Nontraditional Epidemiologic Approaches in the Analysis of Gene Environment Interaction: Case-Control Studies with No Controls! Am J Epidemiol. 1996;144(3):207-213. doi:10.1093/oxfordjournals.aje.a008915

6. Liedtke C, Mazouni C, Hess KR, et al. Response to neoadjuvant therapy and long-term survival in patients with triple-negative breast cancer. J Clin Oncol. 2008;26(8):12751281. doi:10.1200/JCO.2007.14.4147

7. Lin NU, Vanderplas A, Hughes ME, et al. Clinicopathologic features, patterns of recurrence, and survival among women with triple-negative breast cancer in the National Comprehensive Cancer Network. Cancer. 2012;118(22):5463-5472.

doi:10.1002/cncr.27581

8. Nielsen TO, Hsu FD, Jensen K, et al. Immunohistochemical and clinical characterization of the basal-like subtype of invasive breast carcinoma. Clin Cancer Res. 2004;10(16):5367-5374. doi:10.1158/1078-0432.CCR-04-0220

9. Millikan RC, Newman B, Tse C-K, et al. Epidemiology of basal-like breast cancer. Breast Cancer Res Treat. 2008;109(1):123-139. doi:10.1007/s10549-007-9632-6

10. Chollet-Hinton L, Olshan AF, Nichols HB, et al. Biology and etiology of young-onset breast cancers among premenopausal African American women: Results from the AMBER Consortium. Cancer Epidemiol Biomarkers Prev. 2017;26(12):1722-1729. doi:10.1158/1055-9965.EPI-17-0450

11. Sweeney C, Bernard PS, Factor RE, et al. Intrinsic subtypes from PAM50 gene expression assay in a population-based breast cancer cohort: differences by age, race, and tumor characteristics. Cancer Epidemiol Biomarkers Prev. 2014;23(5):714-724. doi:10.1158/1055-9965.EPI-13-1023

12. Ambrosone CB, Zirpoli G, Ruszczyk M, et al. Parity and breastfeeding among AfricanAmerican women: differential effects on breast cancer risk by estrogen receptor status in the Women's Circle of Health Study. Cancer Causes Control. 2014;25:259-265. 
doi:10.1007/s10552-013-0323-9

13. Palmer JR, Boggs DA, Wise LA, Ambrosone CB, Adams-Campbell LL, Rosenberg L. Parity and lactation in relation to estrogen receptor negative breast cancer in African American women. Cancer Epidemiol Biomarkers Prev. 2011;20(9):1883-1891. doi:10.1158/1055-9965.EPI-11-0465

14. Warner ET, Colditz GA, Palmer JR, Partridge AH, Rosner BA, Tamimi RM. Reproductive factors and risk of premenopausal breast cancer by age at diagnosis: Are there differences before and after age 40? Breast Cancer Res Treat. 2013;142(1):165-175. doi:10.1007/s10549-013-2721-9

15. Ambrosone CB, Zirpoli G, Hong C-C, et al. Important Role of Menarche in Development of Estrogen Receptor-Negative Breast Cancer in African American Women. JNCI J Natl Cancer Inst. 2015;107(9). doi:10.1093/jnci/djv172

16. Bertrand KA, Bethea TN, Adams-Campbell LL, Rosenberg L, Palmer JR. Differential Patterns of Risk Factors for Early-Onset Breast Cancer by ER Status in African American Women. Cancer Epidemiol Biomarkers Prev. 2017;26(2):270-277. doi:10.1158/10559965.EPI-16-0692

17. Bethea TN, Rosenberg L, Hong C-C, et al. A case-control analysis of oral contraceptive use and breast cancer subtypes in the African American Breast Cancer Epidemiology and Risk Consortium. Breast Cancer Res. 2015;17:22. doi:10.1186/s13058-015-0535-X

18. Bandera E V., Chandran U, Hong C-C, et al. Obesity, body fat distribution, and risk of breast cancer subtypes in African American women participating in the AMBER Consortium. Breast Cancer Res Treat. 2015;150(3):655-666. doi:10.1007/s10549-015$3353-\mathrm{z}$

19. Ma H, Ursin G, Xu X, et al. Body mass index at age 18 years and recent body mass index in relation to risk of breast cancer overall and ER/PR/HER2-defined subtypes in white women and African-American women: a pooled analysis. Breast Cancer Res. 2018;20(1):5. doi:10.1186/s13058-017-0931-5

20. Kwan ML, Kushi LH, Weltzien E, et al. Epidemiology of breast cancer subtypes in two prospective cohort studies of breast cancer survivors. Breast Cancer Res. 2009;11(3). doi:10.1186/bcr2261

21. Stead LA, Lash TL, Sobieraj JE, et al. Triple-negative breast cancers are increased in black women regardless of age or body mass index. Breast Cancer Res. 2009;11(2). doi:10.1186/bcr2242

22. Li CI, Beaber EF, Tang MTC, Porter PL, Daling JR, Malone KE. Reproductive factors and risk of estrogen receptor positive, triple-negative, and HER2-neu overexpressing breast cancer among women 20-44 years of age. Breast Cancer Res Treat. 2013;137(2):579-587. doi:10.1007/s10549-012-2365-1

23. Trivers KF, Lund MJ, Porter PL, et al. The epidemiology of triple-negative breast cancer, including race. Cancer Causes Control. 2009;20(7):1071-1082. doi:10.1007/s10552-0099331-1 
24. Shinde SS, Forman MR, Kuerer HM, et al. Higher parity and shorter breastfeeding duration. Cancer. 2010;116(21):4933-4943. doi:10.1002/cncr.25443

25. Allott EH, Cohen SM, Geradts J, et al. Performance of Three-Biomarker Immunohistochemistry for Intrinsic Breast Cancer Subtyping in the AMBER Consortium. Cancer Epidemiol Biomarkers Prev. 2016;25(3):470-478. doi:10.1158/1055-9965.EPI-150874

26. Nielsen TO, Parker JS, Leung S, et al. A Comparison of PAM50 Intrinsic Subtyping with Immunohistochemistry and Clinical Prognostic Factors in Tamoxifen-Treated Estrogen Receptor-Positive Breast Cancer. Clin Cancer Res. 2010;16(21):5222-5232. doi:10.1158/1078-0432.CCR-10-1282

27. Bastien RR, Rodríguez-Lescure Á, Ebbert MT, et al. PAM50 breast cancer subtyping by RT-qPCR and concordance with standard clinical molecular markers. BMC Med Genomics. 2012;5. doi:10.1186/1755-8794-5-44

28. Goldhirsch A, Winer EP, Coates AS, et al. Personalizing the treatment of women with early breast cancer: highlights of the St Gallen International Expert Consensus on the Primary Therapy of Early Breast Cancer 2013. 2013. doi:10.1093/annonc/mdt303

29. Allott EH, Geradts J, Cohen SM, et al. Frequency of breast cancer subtypes among African American women in the AMBER consortium. Breast Cancer Res. 2018;20(1):12. doi:10.1186/s13058-018-0939-5

30. Palmer JR, Ambrosone CB, Olshan AF. A collaborative study of the etiology of breast cancer subtypes in African American women: the AMBER consortium. Cancer Causes Control. 2014;25(3):309-319. doi:10.1007/s10552-013-0332-8

31. Anderson WF, Pfeiffer RM, Dores GM, Sherman ME. Comparison of Age Distribution Patterns for Different Histopathologic Types of Breast Carcinoma. Cancer Epidemiol Biomarkers Prev. 2006;15(10):1899-1905. doi:10.1158/1055-9965.EPI-06-0191

32. Pfeiffer RM, Carroll RJ, Wheeler W, Whitby D, Mbulaiteye S. Combining assays for estimating prevalence of human herpesvirus 8 infection using multivariate mixture models. Biostatistics. 2008;9(1):137-151. doi:10.1093/biostatistics/kxm018

33. Tamimi RM, Colditz GA, Hazra A, et al. Traditional breast cancer risk factors in relation to molecular subtypes of breast cancer. Breast Cancer Res Treat. 2012;131(1):159-167. doi:10.1007/s10549-011-1702-0

34. Palmer JR, Viscidi E, Troester MA, et al. Parity, lactation, and breast cancer subtypes in African American Women: Results from the AMBER Consortium. J Natl Cancer Inst. 2014;106(10). doi:10.1093/jnci/dju237

35. Fortner RT, Sisti J, Chai B, et al. Parity, breastfeeding, and breast cancer risk by hormone receptor status and molecular phenotype: results from the Nurses' Health Studies. Breast Cancer Res. 2019;21(1):40. doi:10.1186/s13058-019-1119-y

36. Holm J, Eriksson L, Ploner A, et al. Assessment of Breast Cancer Risk Factors Reveals Subtype Heterogeneity. Cancer Res. 2017;77(13):3708-3717. doi:10.1158/00085472.CAN-16-2574 
37. Kwan ML, Bernard PS, Kroenke CH, et al. Breastfeeding, PAM50 Tumor Subtype, and Breast Cancer Prognosis and Survival. J Natl Cancer Inst. 2015;107(7).

doi:10.1093/jnci/djv087

38. Islami F, Liu Y, Jemal A, et al. Breastfeeding and breast cancer risk by receptor status-a systematic review and meta-analysis. Ann Oncol. 2015;26(12):2398-2407.

doi:10.1093/annonc/mdv379

39. Ma H, Ursin G, Xu X, et al. Reproductive factors and the risk of triple-negative breast cancer in white women and African-American women: A pooled analysis. Breast Cancer Res. 2017;19(1). doi:10.1186/s13058-016-0799-9

40. Sisti JS, Collins LC, Beck AH, Tamimi RM, Rosner BA, Eliassen AH. Reproductive risk factors in relation to molecular subtypes of breast cancer: Results from the nurses' health studies. Int J cancer. 2016;138(10):2346-2356. doi:10.1002/ijc.29968

41. Chen L, Li CI, Tang MTC, et al. Reproductive factors and risk of luminal, HER2overexpressing, and triple-negative breast cancer among multiethnic women. Cancer Epidemiol Biomarkers Prev. 2016;25(9):1297-1304. doi:10.1158/1055-9965.EPI-15-1104

42. Phipps AI, Chlebowski RT, Prentice R, et al. Body Size, Physical Activity, and Risk of Triple-Negative and Estrogen Receptor-Positive Breast Cancer. 2011. doi:10.1158/10559965.EPI-10-0974

43. Bandera E V, Maskarinec G, Romieu I, John EM. Racial and Ethnic Disparities in the Impact of Obesity on Breast Cancer Risk and Survival: A Global Perspective. Adv Nutr. 2015;6(6):803-819. doi:10.3945/an.115.009647

44. Gaudet MM, Gierach GL, Carter BD, et al. Pooled Analysis of Nine Cohorts Reveals Breast Cancer Risk Factors by Tumor Molecular Subtype. Cancer Res. 2018;78(20):60116021. doi:10.1158/0008-5472.CAN-18-0502

45. Allen JA, Li R, Scanlon KS, et al. Progress in increasing breastfeeding and reducing racial/ethnic differences - United States, 2000-2008 births. Morb Mortal Wkly Rep. 2013;62(5):77-80.

46. Martin JA, Hamilton BE, Osterman MJK. Births in the United States, 2018 Key Findings Data from the National Vital Statistics System.; 2018. https://www.cdc.gov/nchs/products/index.htm. Accessed November 24, 2019.

47. Park B, Choi JY, Sung HK, et al. Attribution to Heterogeneous Risk Factors for Breast Cancer Subtypes Based on Hormone Receptor and Human Epidermal Growth Factor 2 Receptor Expression in Korea. Med (United States). 2016;95(14). doi:10.1097/MD.0000000000003063

48. Gammon MD, Hibshoosh H, Terry MB, et al. Oral contraceptive use and other risk factors in relation to HER-2/neu overexpression in breast cancer among young women. Cancer Epidemiol Biomarkers Prev. 1999;8(5):413-419.

http://www.ncbi.nlm.nih.gov/pubmed/10350436. Accessed November 24, 2019.

49. Cerne JZ, Ferk P, Frkovic-Grazio S, Leskosek B, Gersak K. Risk factors for HR- and HER2-defined breast cancer in Slovenian postmenopausal women. Climacteric. 
2012;15(1):68-74. doi:10.3109/13697137.2011.609286

50. Anderson WF, Rosenberg PS, Prat A, Perou CM, Sherman ME. How Many Etiological Subtypes of Breast Cancer: Two, Three, Four, Or More? JNCI J Natl Cancer Inst. 2014;106(8):dju165-dju165. doi:10.1093/jnci/dju165

51. Anderson WF, Rosenberg PS, Prat A, Perou CM, Sherman ME. How many etiological subtypes of breast cancer: two, three, four, or more? J Natl Cancer Inst. 2014;106(8). doi:10.1093/jnci/dju165

52. Matsuno RK, Anderson WF, Yamamoto S, et al. Early- and late-onset breast cancer types among women in the United States and Japan. Cancer Epidemiol Biomarkers Prev. 2007;16(7):1437-1442. doi:10.1158/1055-9965.EPI-07-0108

53. Allott EH, Shan Y, Chen M, et al. Bimodal age distribution at diagnosis in breast cancer persists across molecular and genomic classifications. Breast Cancer Res Treat. September 2019. doi:10.1007/s10549-019-05442-2 